\title{
APPLICATION OF 3D ROUGHNESS PARAMETERS FOR WEAR INTENSITY CALCULATIONS
}

\author{
N. Bulaha*, O. Linins, A. Avisane \\ Institute of Mechanics and Mechanical Engineering \\ Riga Technical University, \\ 6B Kipsalas Str., LV-1048, Riga, LATVIA \\ *e-mail:mmk@rtu.Iv
}

In this paper, calculations of 3D parameter $V m$ (material volume) of surfaces with irregular roughness and comparison with experimental data were performed, with further application of this parameter in calculations of wear intensity. First, using Mountains Map software for profilometric measurements, 3D roughness processing and determination of material volume $\mathrm{Vm}$ at specific relative levels $\gamma$ were performed. The next step was an additional analysis of the distribution of surface ordinates using a theoretical and experimental Laplace function. The given check confirmed that for mostly surfaces with irregular roughness the ordinate distribution corresponds to the normal Gaussian distribution law, but in cases when the asymmetry of the ordinate distribution function goes outside the permissible limits $(|\Delta S s k|>10 \%)$, errors $>10 \%$ occur. On this basis, the mathematical formula of the material volume $V m$ was derived, and the obtained calculations were compared with the measured values. The results showed that the calculated values of the parameter $V m$ were very close to the experimental data $(|\Delta V m|<10 \%)$, while at the relative level $\gamma=+3$, errors occurred that was related to the deviation from the normal distribution law. It was concluded that the given parameter could be used in the calculations of linear wear intensity, knowing the relative level $\gamma$.

Keywords: $3 D$ roughness parameters, friction, material volume, wear. 
Nowadays, the issue of surface wear does not lose its relevance because all the time designers and technologists are trying to find effective solutions to increase the wear resistance of surfaces. As it is known, the wear intensity is influenced by several factors / parameters: the material and its properties, load, lubrication conditions, and roughness. The surface quality is very important in this regard because the type of surface treatment and the roughness parameters largely determine the service life of the friction pair.

Surfaces for the friction pairs of the machine apparatus mainly are treated with abrasive materials, which ensure the required surface smoothness and accuracy. Surfaces, after such treatment, are characterised by irregular arrangement of microirregularities, and roughness parameters for such surfaces are calculated using normal random field theory [1].

At this time, Standard ISO 25178-2, which defines 3D surface roughness param- eters, does not give a complete picture of the physical meaning of these parameters. No relationships are shown between the surface roughness parameters, which would help determine the factors that affect a particular parameter and the way they can be changed / improved.

In the calculations of linear wear intensity, one of the important roughness parameters is the volume of the deformed material. To determine it, the following tasks have been performed in the given study:

1. Compliance check of the ordinate distribution function of surfaces with irregular roughness to the normal distribution law using an additional method Laplace function analysis.

2. Determination of roughness parameter $\mathrm{Vm}$ at different relative levels $\gamma$ in the Mountains Map software.

3. Output of parameter $V m$, comparing the calculated and experimental values.

4. Calculations of linear wear intensity using the roughness parameter $V m$.

\section{SURFACE ORDINATE DISTRIBUTION}

In the given study, six different surfaces were studied: flat ground, polished, lapped, shot peened, sandblasted and after electroerosion.

As it was mentioned above, surface roughness after treatment with abrasive materials was irregular. For this type of surface, it is important to check compliance with the normal distribution law in order to make further calculations. In scientific works [2], the compliance of surface ordinate distribution function to the normal distribution law was substantiated using such criteria as:
1. asymmetry Ssk of the surface ordinate distribution function;

2. the excess $S k u$ of the surface ordinate distribution function;

3. Pearson criterion;

4. correlation function.

An additional criterion that can be used to solve this issue is the Laplace function, which represents the area of a material at a given level $c$ (in percent).

In the general case, the Laplace function is expressed by Eq. (1):

$\Phi(x)=\frac{1}{\sqrt{2 \pi}} \int_{0}^{x} e^{\frac{-z^{2}}{2}} d z$. 
The parameter given in the standard ISO $25178-2$ is defined as a ratio of the area of the material at a height $c$ to the evaluation area (Fig. 1).

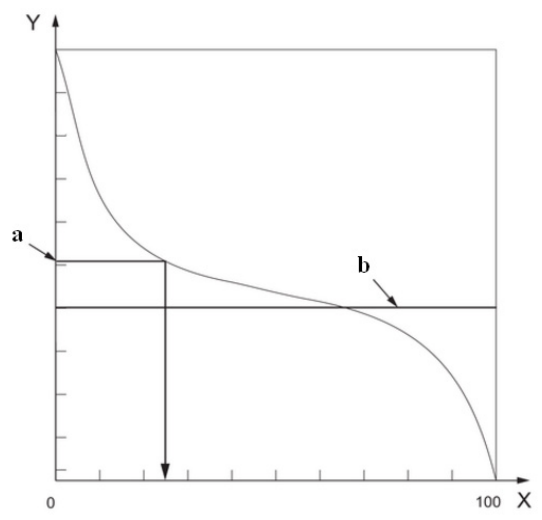

Fig. 1. Areal material ratio:

$\mathrm{X}$ - areal material ratio $\operatorname{Smr}(c)$, in percent; $\mathrm{Y}$ - height; $\mathrm{a}$ - level $c$; b - reference plane [3].

The graph of the Laplace function can faces at the levels $c$, using Eq. (2): be constructed for any of the studied sur-

$E\{\operatorname{Smr}(c)\}=\frac{1}{A} \iint_{\Omega} \xi\{r(z, c)\}=1-\Phi\left(\frac{c}{s q}\right)$,

where $A$-nominal surface area, $\mathrm{mm}^{2} ; c-1$ evel, $\mu \mathrm{m} ; S q$ - root mean square height, $\mu \mathrm{m}$.

$c=\gamma \cdot S q$,

where $\gamma$-relative level. $\gamma_{\text {standart }}=3,2,1,0,-1,-2,-3$.

Using the Mountains Map software [4], the area of the material at the relative levels $\gamma=+3,+2,+1,0,-1,-2,-3$ was determined for the studied surfaces. In Table 1 , the calculated and measured values of the parameter $\operatorname{Smr}(c)$ for a flat ground surface were summarised and the absolute error was calculated. The calculated values of this parameter are fully compliant with the Laplace function indicators.

Table 1. Comparison of Theoretical and Experimental Values of Roughness Parameter Smr(c) for Flat Ground Surface

\begin{tabular}{|c|c|c|c|}
\hline$\gamma$ & $\operatorname{Smr}(c)_{\text {calc }} \%$ & $\operatorname{Smr}(c)_{\text {measured }} \%$ & $|\Delta \operatorname{Smr}(c)|, \%$ \\
\hline+3 & 0.13 & 0.12 & 8.30 \\
\hline+2 & 2.28 & 2.20 & 3.30 \\
\hline+1 & 15.87 & 17.30 & 9.04 \\
\hline 0 & 50.00 & 47.90 & 4.20 \\
\hline-1 & 84.13 & 85.40 & 1.50 \\
\hline-2 & 97.72 & 97.80 & 0.08 \\
\hline-3 & 99.87 & 100.00 & 0.14 \\
\hline
\end{tabular}


In Fig. 2, the graphical representation of the experimental values of the parameter $\operatorname{Smr}(c)$ and the Laplace function are shown. It can be concluded that for the given sur- face the distribution of ordinates very exactly corresponds to the normal distribution law and falls within the deviation range of $+/-10 \%$.

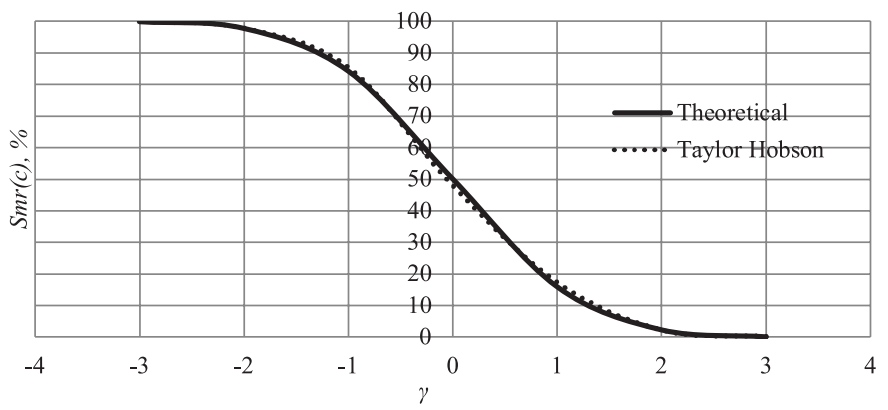

Fig. 2. Graphical representation of the calculated and experimental values of the parameter $\operatorname{Smr}(c)$.

In turn, for the other studied surfaces there are deviations from the standard values of the Laplace function at the upper relative levels $\gamma=+2$ and +3 (Fig. 3 ). The value of the absolute error $\Delta \operatorname{Smr}(c)$ is greater than $10 \%$ in several cases. This result is influ- enced by the asymmetry Ssk of the surface ordinate distribution function. The experimental values of $S m r(c)$ at $S s k>0.05$ and $S s k$ $<-0.05$ differ from the theoretical ones by up to $60 \%$.

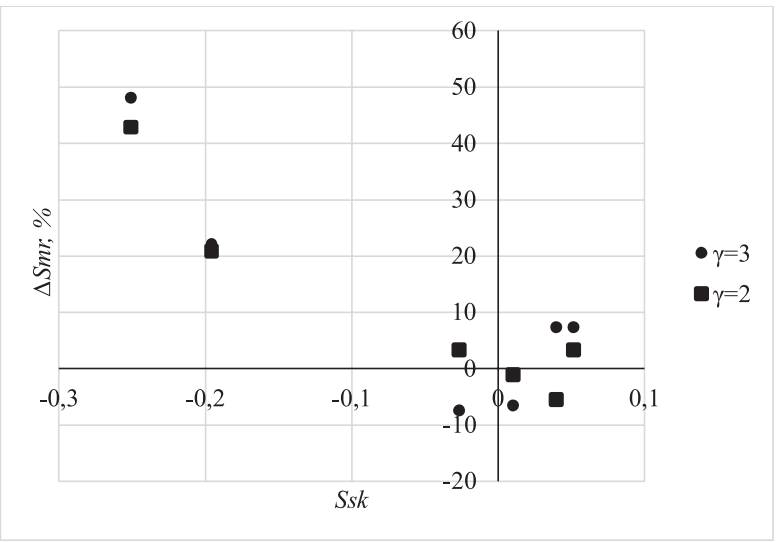

Fig. 3. Influence of asymmetry $S s k$ of ordinate distribution function on absolute error $|\Delta S m r|$.

\section{CALCULATION OF MATERIAL VOLUME Vm}

The volume of the micro-irregularities of the rough surface above the level $c$ is a very important feature in the calculations of the contact deformation. The volume of surface material at a given level expresses the amount of deformed material in the friction process.

The average volume of material can be obtained analogously to the surface profile area by integrating the surface cross-sectional area $A(c)$ at levels $c$ [5]. 
$V m=\int_{c}^{\infty} A(c) d c$

Due to the fact that

$A(c)=\operatorname{Smr}(c) \cdot A a$,

the mathematically expected value of the material volume, taking into account Eq. (2), will be equal to:

$$
\begin{aligned}
& E\{V m\}=A a \int_{c}^{\infty} E\{\operatorname{Smr}(c)\} d c, \\
& E\{V m\}=A a \int_{c}^{\infty}\left[1-\Phi\left(\frac{c}{s q}\right)\right] d c, \\
& E\{V m\}=S q\left\{\frac{1}{\sqrt{2 \pi}} \exp \left(-\frac{c^{2}}{2 S q^{2}}\right)-\frac{c}{S q}\left[1-\Phi\left(\frac{c}{s q}\right)\right]\right\} .
\end{aligned}
$$

Expression (8) indicates that the material volume $V m$ varies depending on the relative level $\gamma$. As $\gamma$ changes from $-\infty$ to $+\infty$, the material volume increases. At $\gamma$ values $-\infty<\gamma<-1$, it can be considered that the volume of deformed material practically does not change according to the linear law.

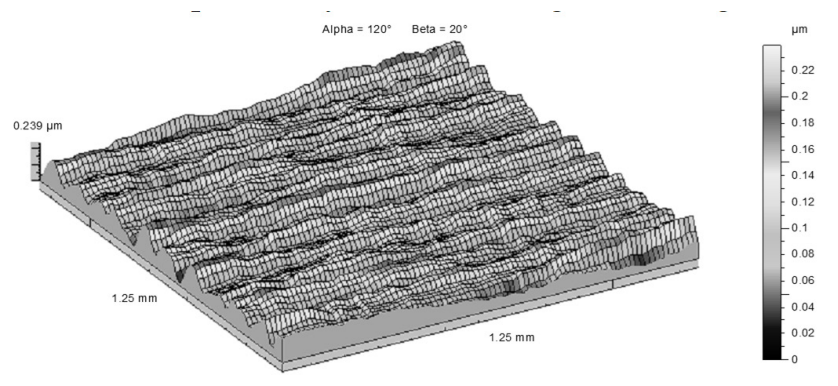

Fig. 4. Topography of a flat ground surface.

In Fig. 4, a flat ground surface is visible, the ordinate distribution of which corresponds to the normal Gaussian distribution law, which was justified in the previous paragraph. For a given surface $V m$ calculations were performed at different levels $c$ subtracted from the mean plane. Theoretical values of material volume were calculated according to Eq. (8), while the experimental data were obtained by Mountains Map soft- ware, using a function "slices" to generate a surface divided into two parts - material and voids. In Fig. 5, the material volume is marked in grey colour, and void volume in black. By selecting the required level, it is possible to obtain the required $\mathrm{Vm}$ values. In addition, this function represents the area of the material at a given level, which corresponds to the values of the parameter $\operatorname{Smr}(c)$. 


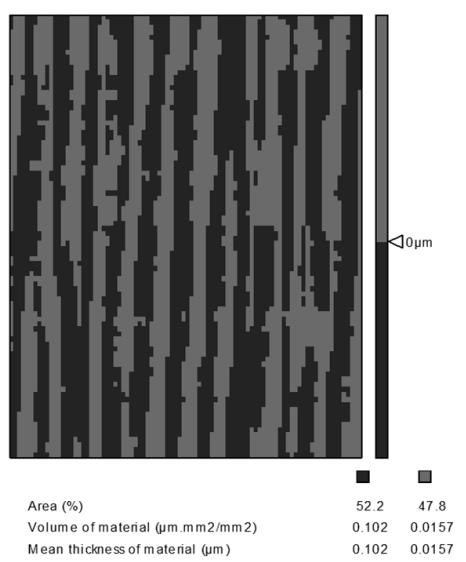

Fig. 5. Representation of surface material and void volume at level $c$.

Table 2 shows the calculated and experimental values of parameter $\mathrm{Vm}$ and their comparison in the form of absolute error for the flat ground surface. At all relative levels, except the highest $(\gamma=+3)$, the calculated values coincide very precisely with the experimental data, and the absolute error falls within the range of $+/-10 \%$. The discrepancy at the relative level $\gamma=+3$ arises because the Ssk value of the ordinate distribution function has a large deviation ( $>10 \%$ ) from the standard values of normal distribution law.

Table 2. Comparison of Theoretical and Experimental Values of Roughness Parameter $V m$ for Flat Ground Surface

\begin{tabular}{|c|c|c|c|}
\hline$\gamma$ & $V m_{\text {calc }} \mathrm{mm}^{3} / \mathrm{mm}^{2}$ & $V m_{\text {measured }} \mathrm{mm}^{3} / \mathrm{mm}^{2}$ & $|\Delta V \mathrm{Vm}|, \%$ \\
\hline+3 & $1.50 \mathrm{E}-08$ & $1.08 \mathrm{E}-08$ & 28.03 \\
\hline+2 & $3.33 \mathrm{E}-07$ & $3.24 \mathrm{E}-07$ & 2.74 \\
\hline+1 & $3.27 \mathrm{E}-06$ & $3.46 \mathrm{E}-06$ & 5.90 \\
\hline 0 & $1.56 \mathrm{E}-05$ & $1.57 \mathrm{E}-05$ & 0.38 \\
\hline-1 & $4.25 \mathrm{E}-05$ & $4.23 \mathrm{E}-05$ & 0.39 \\
\hline-2 & $7.87 \mathrm{E}-05$ & $7.87 \mathrm{E}-05$ & 0.04 \\
\hline-3 & $1.18 \mathrm{E}-04$ & $1.18 \mathrm{E}-04$ & 0.33 \\
\hline
\end{tabular}

Graphically, the experimental and theoretical values of the parameter $\mathrm{Vm}$ are shown in Fig. 6. In the graph, we can see only those levels, at which deformations during friction can actually occur depending on the applied load [6].

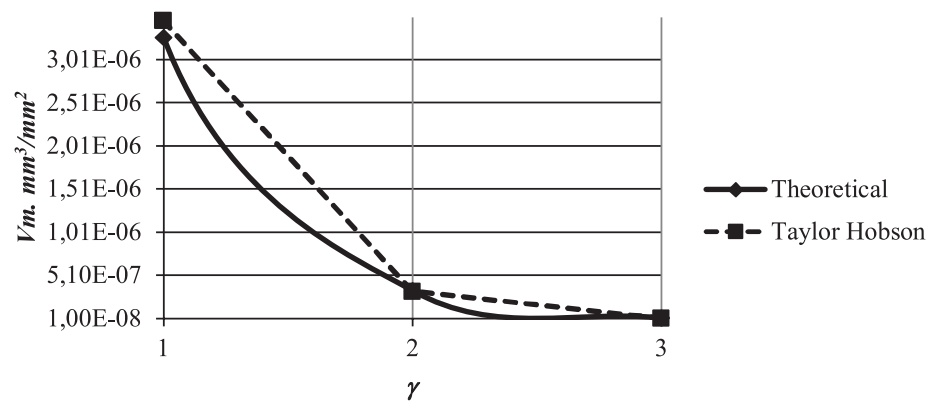

Fig. 6. Graphical representation of the calculated and experimental values of the parameter $V m$. 
Calculations of material volume $\mathrm{Vm}$ and comparison with experimental data were performed for all six studied surfaces to understand the extent to which the asymmetry of the ordinate distribution function affected the results. From the data in Table
3 , it can be concluded that very large errors between theoretical and experimental values occur at the relative levels $\gamma=+2$ and +3 ; it is also related to the deviations of the asymmetry $S s k$.

Table 3. Influence of Asymmetry Ssk of Ordinate Distribution Function on Absolute Error $|\Delta V m|$

\begin{tabular}{|l|c|c|c|c|c|}
\hline \multirow{2}{*}{$\begin{array}{l}\text { No. } \\
\text { Nr. }\end{array}$} & $\begin{array}{c}\text { Type of surface } \\
\text { treatment }\end{array}$ & \multirow{2}{*}{$S s k$} & \multicolumn{3}{|c|}{$|\Delta V m|, \%$} \\
\cline { 3 - 6 } & & $\gamma=+3$ & $\gamma=+2$ & $\gamma=+1$ \\
\hline 1 & Flat grinding & 0.051 & 28.03 & 2.74 & 5.9 \\
\hline 2 & Lapping & 0.039 & 14.50 & 0.28 & 1.16 \\
\hline 3 & Sand blasting & -0.196 & 2.53 & 23.55 & 8.95 \\
\hline 4 & Electro erosion & -0.176 & 53.79 & 40.79 & 9.26 \\
\hline 5 & Shot peening & -0.026 & 17.42 & 1.31 & 1.31 \\
\hline 6 & Polishing & -0.247 & 98.41 & 86.76 & 3.83 \\
\hline
\end{tabular}

\section{CALCULATION OF WEAR INTENSITY $J_{H}$}

In the given study, the analysis of the surface contacting process was performed using the equivalent surface. The application of such a method for solving engineering tasks has been justified in several studies [5]-[7].

In general, there is a direct deformation of the material volume $\mathrm{Vm}$ in the contact zones, but it will not localize in a specific volume, but will spread deeper in the body of the micro-irregularity. In turn, it is substantiated that the deformation spread factor at the deeper layers of the material can be disregarded.

According to [8], the linear wear intensity $J_{h}$ is determined by Eq. (9):

$E\left\{J_{h}\right\}=\frac{V m}{n \cdot d \cdot A a}$

where $V m$ - material volume, $\mathrm{mm}^{3} / \mathrm{mm}^{2}$;

$n$ - a number of cycles to failure;

$d$ - contact length, mm;

$A a$ - nominal contact area, $\mathrm{mm}^{2}$.

In Eq. (10), the roughness parameter $V m$, which expresses the amount of deformed material, is figured out. Knowing the relative level $\gamma$, this parameter can be easily determined for any surface. In turn, at the beginning of solving an engineering task, it is important to determine how the micro-irregularities of the studied surface will be deformed.

The contact area to a greater extent is characterised by the ability of surface microirregularities to be elastically deformed, what can be described by the contact type criterion $C C$ [6]. The calculation formula of $C C$ includes roughness parameters - $S a$, $R S m$ and material mechanical properties micro-hardness and elastic constant:

$C C=\frac{R S m \cdot \theta \cdot H_{\mu}}{S a}$,

where $R S m$ - an average step of microirregularities, $\mathrm{mm}$;

$\theta$ - elastic constant of material, $\mathrm{m}^{2} / \mathrm{MN}$;

$H_{\mu}$ - surface microhardness, $\mathrm{N} / \mathrm{mm}^{2}$;

$S a$-arithmetic mean height, $\mu \mathrm{m}$;

$\theta=\frac{1-\mu_{2}^{2}}{E_{2}}$,

where $\mu$ - Poisson's ratio;

$E$ - elastic modulus, $\mathrm{MN} / \mathrm{m}^{2}$. 
If the value of the contact type criterion is $>1.7$, then the condition of elastic deformation is fulfilled, but if $C C<0.7$, the contact is plastic.

Accordingly, depending on the type of contact, the level of deformation can be expressed by the following equations:

$$
\begin{aligned}
& F_{1}\{\gamma\}=\left(\frac{q \cdot \theta_{\text {sum }}}{k_{\text {elast }}}\right) \cdot\left(\frac{R S m}{S a}\right), \\
& F_{2}\{\gamma\}=\frac{q}{H \cdot k_{\text {plast }}},
\end{aligned}
$$

where $F_{1,2}(\gamma)$-tabulated functions [8]; $q-\operatorname{load}, \mathrm{MN} / \mathrm{m}^{2}$;

$k_{\text {elast, plast }}$ - a coefficient that depends on the anisotropy of the surface (the parameter Str); $\theta_{\text {sum }}$ - total elastic constant of material, $\mathrm{m}^{2} / \mathrm{MN}$.

The total elastic constant is calculated according to the following equation:

$\theta_{\text {sum }}=\frac{1-\mu_{1}^{2}}{E_{1}}+\frac{1-\mu_{2}^{2}}{E_{2}}$.

The number of cycles to failure also depends on the type of deformation - elastic or plastic, and $n_{e l}$ and $n_{\text {plast }}$ can be expressed by the equations:

$E\left\{n_{e l}\right\}=\left(\frac{3 \pi \theta \sigma_{0}}{4 k f} \cdot \sqrt{\frac{r}{S z \cdot \varepsilon}}\right)^{t_{e l}}$,

$\mathrm{E}\left\{n_{\text {plast }}\right\}=\left(\frac{e_{0}}{\sqrt{2}} \sqrt{\frac{\sigma_{T}-2 f H_{\mu}}{\sigma_{T}+2 f H_{\mu}} \cdot \frac{r}{S z \cdot \varepsilon}}\right)^{t_{\text {plast }}}$

where $e_{0}, \sigma_{0}-$ extrapolated values of the fatigue curve, $\mathrm{MN} / \mathrm{m}^{2}$;

$k$ - constant depending on friction-fatigue characteristics, $\mathrm{k}=3(1+\mu)$;

$f$-coefficient of friction;

$t_{\text {el, plast }}$ - fatigue curve parameters;

$\sigma_{T}$ - material yield strength, $\mathrm{N} / \mathrm{mm}^{2}$;

$r$ - mean summit curvature [1], $\mathrm{mm}^{-1}$;

$S z$ - max height of surface, $\mu \mathrm{m}$;

$\varepsilon$ - relative convergence, $\mathrm{mm}^{-2}$.

$r=\frac{1}{2} \pi^{2} \cdot S q \cdot\left(\frac{4}{R S m^{2}}\right)\left(1+S t r^{2}\right) \gamma$, $\varepsilon=1,54 \cdot\left(\frac{r}{S z}\right)^{\frac{1}{5}}(q \cdot \theta)^{\frac{2}{5}}$

Determination of the wear intensity according to Eq. (9) requires the study of the contact size, which is expressed as the length of the actual contact area in the direction of friction. According to [8], the mathematically expected value of the contact length $E\{d\}$ is determined by the equation:

$E\{d\}=R \operatorname{Sm}[1-\Phi(\gamma)] e^{-\frac{\gamma^{2}}{2}}$.

Linear wear is expressed by the following formula:

$h=J_{h} \cdot L_{t r}$,

where $L_{t r}-$ a friction path, $\mu \mathrm{m}$;

$L_{t r}=V \cdot t$,

where $V$ - traverse speed, $\mathrm{m} / \mathrm{min}$;

$t$ - working time, st.

Thus, knowing the output calculation data: roughness parameters, physicalmechanical, friction-fatigue and constructive characteristics of friction pair materials, it is possible to calculate the linear wear intensity according to Eq. (9). In this study, wear calculations for a lathe friction pair guide-table (Fig. 7) were made.

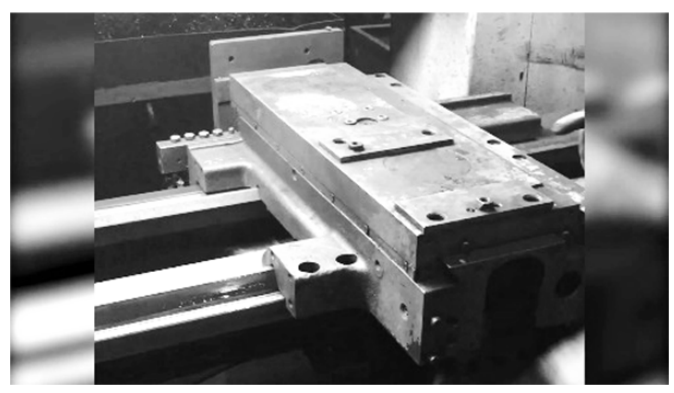

Fig. 7. Friction pair guide - table.

Table 4 summarises the data on the material characteristics of the friction pair, 
as well as tabulated values of different coefwas calculated for the sliding guide - the ficients. In this example, the wear intensity part that absorbs the load during contact.

Table 4. Output Data of Friction-Pair Guide-Table for Wear Intensity Determination

\begin{tabular}{|c|c|c|c|c|}
\hline \multirow{2}{*}{\multicolumn{2}{|c|}{$\begin{array}{l}\text { Parameters } \\
\text { Cast iron } 300 \text { ISO } 185\end{array}$}} & Guide & Table & \multirow{3}{*}{\begin{tabular}{|l|} 
Units \\
$\mu \mathrm{m}$
\end{tabular}} \\
\hline & & \multicolumn{2}{|l|}{$\begin{array}{l}\text { Steel C45 } \\
\text { EN 10083-2 }\end{array}$} & \\
\hline \multirow{7}{*}{$\begin{array}{l}\text { Roughness param- } \\
\text { eters }\end{array}$} & $S a$ & 0.24 & 0.24 & \\
\hline & $S q$ & 0.3 & 0.3 & $\mu \mathrm{m}$ \\
\hline & $R S m_{1}$ & 0.12 & 0.12 & $\mathrm{~mm}$ \\
\hline & $\mathrm{RSm}_{2}$ & 0.6 & 0.6 & $\mathrm{~mm}$ \\
\hline & Str & 0.22 & 0.24 & - \\
\hline & $V m$ & $1.19 \cdot 10^{-6}$ & - & $\mathrm{mm}^{3} / \mathrm{mm}^{2}$ \\
\hline & $S z$ & 2.25 & - & $\mu \mathrm{m}$ \\
\hline \multirow{3}{*}{$\begin{array}{l}\text { Physical-mechanical } \\
\text { characteristics }\end{array}$} & $E$ & $1.3 \cdot 10^{5}$ & $2.1 \cdot 10^{5}$ & $\mathrm{MN} / \mathrm{m}^{2}$ \\
\hline & $\mu$ & 0.25 & 0.3 & - \\
\hline & $H_{\mu}$ & 1800 & 1960 & $\mathrm{~N} / \mathrm{mm}^{2}$ \\
\hline \multirow{4}{*}{$\begin{array}{l}\text { Friction-fatigue } \\
\text { characteristics }\end{array}$} & $\sigma_{0}$ & 1600 & - & $\mathrm{MN} / \mathrm{m}^{2}$ \\
\hline & $t_{e l}$ & 6.45 & - & - \\
\hline & $f$ & \multicolumn{2}{|l|}{0.1} & - \\
\hline & $k$ & \multicolumn{2}{|l|}{3.75} & - \\
\hline \multirow{3}{*}{$\begin{array}{l}\text { Constructive charac- } \\
\text { teristics }\end{array}$} & $q$ & \multicolumn{2}{|l|}{0.5} & $\mathrm{MN} / \mathrm{m}^{2}$ \\
\hline & $V$ & \multicolumn{2}{|l|}{0.5} & $\mathrm{~m} / \mathrm{min}$ \\
\hline & $t$ & \multicolumn{2}{|l|}{5000} & st. \\
\hline
\end{tabular}

1. First, the elastic constant of the material was determined according to Eq. (11):

$\theta=\frac{1-0.25^{2}}{1.3 \cdot 10^{5}}=7.21 \cdot 10^{-6}\left(\mathrm{~m}^{2} / \mathrm{MN}\right)$.

2. The contact type criterion $C C$ according to Eq. (10):

$C C=\frac{0.12 \cdot 7 \cdot 21 \cdot 10^{-6} \cdot 1800}{0.24 \cdot 10^{-3}}=6.49$.

It can be assumed that in this case the elastic contact is provided $(C C>1.7)$.

3. The relative level $\gamma$ according to Eq. (12) in the case of elastic contact is determined as follows:

$F_{1}\{\gamma\}=\left(\frac{0.5 \cdot 1.15 \cdot 10^{-5}}{0.4562}\right) \cdot\left(\frac{0.12 \cdot 10^{3}}{0.24}\right)=0.06 \cdot 10^{-2}$,

where $k_{\text {elast }}=0.4562-$ a tabulated value obtained at Str $=0.12 / 0.6=0.2[8]$. 
In turn, the total elastic constant of the contact is equal to:

$\theta_{\text {sum }}=\frac{1-0.3^{2}}{2.1 \cdot 10^{5}}+\frac{1-0.25^{2}}{1.3 \cdot 10^{5}}=1.15 \cdot 10^{-5}\left(\mathrm{~m}^{2} / \mathrm{MN}\right)$.

4. In this case, the calculated relative level $\gamma=2.3$ [8].

5. The mean summit curvature is equal to:

$r=\frac{1}{2} \pi^{2} \cdot 0.3 \cdot\left(\frac{4}{0.12^{2}}\right)\left(1+0.2^{2}\right) \cdot 2.3=0.99\left(\mathrm{~mm}^{-1}\right)$.

6. The relative convergence was determined by Eq. (18):

$\varepsilon=1.54 \cdot\left(\frac{0.99}{2.25 \cdot 10^{-3}}\right)^{\frac{1}{5}}\left(0.5 \cdot 7.21 \cdot 10^{-6}\right)^{\frac{2}{5}}=2.18 \cdot 10^{-3}\left(\mathrm{~mm}^{-2}\right)$.

7. The number of cycles to failure was determined by Eq. (15):

$E\left\{n_{e l}\right\}=\left(\frac{3 \pi \cdot 7.21 \cdot 10^{-6} \cdot 1600}{4 \cdot 3.75 \cdot 0.1} \cdot \sqrt{\frac{0.99}{2.25 \cdot 10^{-3} \cdot 2.18 \cdot 10^{-3}}}\right)^{6,45}=5693844682$.

8. The value of the contact length is equal to:

$d=0.12 \cdot[1-\Phi(2.3)] e^{-\frac{2.3^{2}}{2}}=9.13 \cdot 10^{-5}(\mathrm{~mm})$.

9. The volume of the deformed material according to theory will be equal to:

$V m=0.001 \cdot 0.3\left\{\frac{1}{\sqrt{2 \pi}} e^{-\frac{2.3^{2}}{2}}-2.3[1-\Phi(2.3)]\right\}=1.1 \cdot 10^{-6}\left(\mathrm{~mm}^{3} / \mathrm{mm}^{2}\right)$.

10. The linear wear intensity was determined by Eq. (9):

$J_{h}=\frac{1.1 \cdot 10^{-6}}{5693844682 \cdot 9.13 \cdot 10^{-5}}=2.12 \cdot 10^{-12}$.

11. The friction path was determined by the traverse speed and working time:

$L_{t r}=0.5 \cdot 5000 * 60=15 \cdot 10^{10}(\mu \mathrm{m})$.

12. The linear wear was determined as follows:

$h=2.12 \cdot 10^{-12} \cdot 15 \cdot 10^{10}=0.32(\mu \mathrm{m})$.

In addition, calculations were per- linear wear intensity $J_{h}=2.3 \cdot 10^{-12}$ and linformed using the measured values of rough- $\quad$ ear wear $h=0.35 \mu \mathrm{m}$. The absolute error in ness parameters $V m$ and Str (Table 4). The both cases is less than $10 \%$. 


\section{CONCLUSIONS}

The study investigated the dependence of linear wear intensity $J_{h}$ of the surface on the volume of the material $\mathrm{Vm}$, the surface texture index Str and the arithmetic mean height $S a$. In addition, the obtained equation of the material volume $\mathrm{Vm}$ contains such parameters as $S q$ - the root mean square height and the level $c$. To check the theoretical relationships of the parameter $V m$, roughness measurements were performed using a 3D measuring equipment Taylor Hobson Talysurf Intra 50. The Mountains Map software was used to process the obtained data. A comparison of the theoretical values and experimental data shows that the absolute error of the surface material volume $|\Delta \mathrm{Vm}|$ at the relative level $\gamma=+3$ in some cases reaches $100 \%$, at the level $\gamma=+2-|\Delta V m|<45 \%$, at lower levels $|\Delta V m|<10 \%$, what can be explained by the asymmetry of the surface ordinate distribution function.

Calculations of linear wear intensity $J_{h}$ show that the offered roughness parameters $\mathrm{Vm}$, Str and $\mathrm{Sa}$ simplify the calculation of wear because using measured values, it is not necessary to calculate each parameter separately.

\section{REFERENCES}

1. Рудзитис, Я. (2007). Контактная механика поверхностей, 2 - ая часть - Микротопография шероховатости поверхности (Surface Contact Mechanics. Part 2 Surface Roughness Microtopography). Riga: Riga Technical University. (In Russian).

2. Bulaha, N. (2018). Calculations of surface roughness 3D parameters for surfaces with irregular roughness. In 17th International Scientific Conference "Engineering for Rural Development” (1437-1444), 23-25 May 2018, Jelgava, Latvia.

3. ISO 25178-2:2012, Geometrical Product Specifications (GPS) - Surface Texture: Areal - Part 2: Terms, Definitions and Surface Texture Parameters.

4. Exploring Surface Texture. (2011). 7th edition. Great Britain: Taylor Hobson Limited. Available at http://www.taylor-hobson.com/ uploads/learningzone/metrologybooks/ Exploring\%20Surface\%20Texture\%20 2014.pdf
5. Рудзитис, Я. А. (2007). Контактная механика поверхностей. Часть 1. (Mechanics of Surface Contact. Part 1). Riga: Riga Technical University. (in Russian).

6. Демкин, Н. Б., Рыжов, Э. В. (1981). Качество поверхности и контакт деталей машин (Surface Quality and Contact of Machine Parts). M: Машиностроение. (in Russian).

7. Longuet-Higgins, M. S. (1957). Statistical Properties of an Isotropic Random Surface. Philosophical Transactions of the Royal Society of London. Series A, Mathematical and Physical Sciences, 250 (975), 157-174.

8. Крагельский, И. В. (1968). Трение и износ. 2-е изд. (Friction and Wear, 2nd ed.) М.: Машиностроение. (in Russian). 